\title{
Apresentação - Ensino de História: entre Bases Nacionais e a formação de professores
}

\section{Presentation - History Teaching: between the National Standards and teacher training}

\author{
Nádia Gaiofatto Gonçalves* \\ Ana Maria Ferreira da Costa Monteiro**
}

\begin{abstract}
RESUMO
Apresentamos os onze artigos que compõem o dossiê Bases Nacionais e Ensino de História, e que contemplam algumas questões relativas a embates, a desafios e a possibilidades que tais documentos envolvem em relação à educação básica e à formação de professores. Os trabalhos foram organizados começando pelo Brasil, passando por uma abordagem comparada da realidade nacional com outros países e, finalmente, tratando de discussões e normativas de outros países, da América do Sul, América Central, América do Norte e Europa. Esperamos contribuir para a reflexão e melhor compreensão desse processo de disputas sobre a educação e, aqui, particularmente, sobre o ensino de História, que deve ser apreendido em perspectiva histórica, e que pode apresentar, como os artigos discutem, tanto similaridades entre diferentes países quanto especificidades, bem como muitos desafios e possibilidades.
\end{abstract}

Palavras-chave: Ensino de História. BNCC. Formação de professores. Educação básica. Currículo.

\begin{abstract}
We present the eleven articles that compose the National Bases and History Teaching dossier, which contemplate some issues related to the conflicts, challenges and possibilities that such documents involve in relation to
\end{abstract}

* Universidade Federal do Paraná. Programa de Pós-Graduação em Educação. Curitiba, Paraná, Brasil. E-mail: nadiagg@ufpr.br - https://orcid.org/0000-0002-9375-8659

${ }^{* * *}$ Universidade Federal do Rio de Janeiro. Rio de Janeiro, Rio de Janeiro, Brasil. E-mail: anammonteiro22@gmail.com - https://orcid.org/0000-0002-8114-3198 
elementary education and teacher training. The works were organized beginning with Brazil, going from a comparative approach of the national reality with other countries, to finally address discussions and regulations in other countries, in South America, Central America, North America and Europe. We hope to contribute to the reflection and better understanding of this process of disputes about education and, particularly about history teaching, which should be understood in a historical perspective, and which may present, as the articles discuss, both similarities between different countries and specificities, as well as many challenges and possibilities.

Keywords: History teaching. National Common Curriculum Base (BNCC). Teacher training. Elementary education. Syllabus.

\section{Introdução}

Com o objetivo de atender a determinações da Lei de Diretrizes e Bases 9394/96 - LDB (BRASIL, 1996), debates foram realizados ao longo dos últimos anos em torno de definições para orientar a construção dos currículos da Educação Básica em escolas brasileiras. A Base Nacional Comum Curricular (BNCC) elaborada e recentemente aprovada (BRASIL, 2017) apresenta permanências e, também, algumas mudanças em relação ao que historicamente tem sido produzido em nosso país quanto a discussões curriculares. Sua elaboração e implementação envolvem questões epistemológicas de cada área de conhecimento, questões pedagógicas e questões políticas. Além disso, a Base foi aprovada em um contexto histórico e político conturbado, em que sua discussão e sua construção coletiva foram seriamente prejudicadas, quando não, ausentes.

A BNCC, apropriada nos Estados e Municípios, gerou e vêm gerando diretrizes curriculares para orientar a ação dos professores nas escolas, a elaboração de exames de avaliação institucional e de acesso às instituições de ensino superior, a produção de livros didáticos por meio dos editais do Programa Nacional do Livro Didático e, também, a formação de professores. Esta última, também recentemente (dezembro/2019), teve aprovadas as Diretrizes Curriculares Nacionais para a Formação Inicial de Professores para a Educação Básica e uma Base Nacional Comum para a Formação Inicial de Professores da Educação Básica.

Situada neste contexto e nestes documentos, focalizamos a disciplina escolar História, que propomos como eixo para a reflexão deste Dossiê, considerando os debates e as tensões que envolveram as discussões relativas à 
sua presença e definição nas Bases para a Educação Básica; suas especificidades, epistemologia e embates próprios, que também estiveram presentes no processo de proposição e de formulação e constituição destes documentos; e nos possíveis desdobramentos na formação para a docência de História, a partir das Diretrizes e da Base para a formação de professores.

Neste sentido, este Dossiê traz trabalhos que abordam a disciplina História e o seu ensino, e sua relação com as referidas Bases, discutindo-o em perspectiva histórica e crítica; contemplando e contextualizando desafios que envolvem as Bases e seu impacto na prática; e refletindo sobre possíveis demandas, embates e desdobramentos acerca da formação inicial de professores para o ensino de História, a partir do atual contexto e diretrizes.

Com tal iniciativa, visamos a contribuir para a sistematização de reflexões e análises acerca dos desafios que envolvem o ensino de História, tanto em perspectiva histórica quanto no atual contexto político e educacional brasileiro, e deste em relação a outros países, da América Latina, da América do Norte e da Europa.

\section{Bases Nacionais e o ensino de História no Brasil}

É incontestável que todo o currículo, e toda disciplina dentro dele, são objetos de embates constantes, que se reconfiguram a cada contexto. De forma bastante acirrada, a partir do final do século XX, a educação brasileira vem sendo objeto de disputas que ultrapassam questões específicas das áreas de conhecimento envolvidas. Silva (2018) aponta como proposições do final dos anos 1990, em grande parte baseadas na ideia de competências, foram sendo gestadas ao longo do tempo e, mais recentemente, recuperadas nas BNCCs, articulando interesses políticos e econômicos. Tais proposições impactam diretamente as disciplinas que compõem esse currículo, em suas finalidades e em suas especificidades epistemológicas.

Abordando a trajetória do ensino de História como código disciplinar, Schmidt (2012) apresenta uma periodização que abarca quatro períodos mais marcantes desta produção no Brasil: "construção do código disciplinar da história (1838-1931); consolidação do código disciplinar da história (1931-1971); crise do código disciplinar da história (1971-1984); reconstrução do código disciplinar da história (1984-?)" (SCHMIDT, 2012, p. 78). Posteriormente, com base em pesquisa sobre a produção acadêmica brasileira relativa ao ensino de História, Gonçalves (2019) afirma que o início do século XXI poderia ser identificado 
como um quinto período, de consolidação do campo sobre ensino de História no Brasil. Toda essa trajetória e produção do campo traz significativas contribuições para a compreensão tanto da disciplina em sua organização e consolidação no currículo escolar quanto de questões que envolvem sua epistemologia, disputas teóricas e políticas, saberes e práticas, entre outros, em um conjunto já bastante amadurecido e dinâmico de pesquisas e reflexões, que, tratando-se da dimensão de políticas educacionais, muitas vezes é desconsiderado ou subestimado mediante outros interesses e referências que estão em jogo. A BNCC é o mais recente documento prescritivo acerca do currículo escolar brasileiro, dentro do qual está a História. Vejamos como os artigos que compõem este dossiê nos auxiliam, na compreensão desses embates, processos e desafios.

$\mathrm{O}$ primeiro artigo do dossiê, intitulado $O$ banho, a água, a bacia e a criança: história e historiadores na defenestração da primeira versão da BNCC de História para o Ensino Fundamental, escrito por Luís Fernando Cerri e Maria Paula Costa, evidencia um grande desafio para o campo ensino de História, as disputas internas, que partem de dificuldades de diálogo entre pesquisadores da História e professores de História, ou pesquisadores da História e pesquisadores do ensino de História, mesmo apesar de todos terem formação em História, ou seja, mesmo que todos sejam historiadores. Esta questão já foi abordada sob diferentes olhares por Martins (2002), Mesquita (2008), Monteiro (2013) e Cerri (2018), entre outros autores, que evidenciaram na própria trajetória do campo Ensino de História um desafio na construção de sua legitimidade, perante a História já consolidada. Tais embates se dão, com maior ou menor força, dentro de Departamentos, Secretarias de Educação, Universidades, e já foram maiores em eventos acadêmicos, como os da Associação Nacional de História (ANPUH), nos quais hoje há espaço garantido para o ensino como campo de pesquisa e de produção de conhecimento.

No caso deste primeiro artigo, os autores evidenciam a recrudescência destes embates, perante a proposição da primeira versão da BNCC, que apresentava uma ruptura com o modelo eurocêntrico quadripartite, historicamente consolidado, que ainda impera nos currículos dos cursos de graduação e na própria educação básica e, que ao final, permaneceu na Base. Estes embates foram ainda mais aguerridos por envolverem elementos e argumentos para além dos acadêmicos e educacionais, como a mídia e questões políticas, muito acirradas neste contexto, em parte pela atuação do movimento Escola sem Partido, mas também pelos desafios e a polarização entre direita e esquerda, que se configurava.

Neste sentido, Cerri e Costa analisam elementos que foram trazidos à baila na discussão sobre a BNCC, centrando maiores esforços nos documentos produzidos no âmbito desse embate, e seus desdobramentos nas versões posteriores da BNCC de História, que acabaram por configurar uma proposta 
por vezes retrógrada em relação às reflexões produzidas no campo e até mesmo a outras diretrizes, como os Parâmetros Curriculares Nacionais (PCNs), do final dos anos de 1990. Porém, esta última versão se constitui como menos incômoda perante alguns interesses que haviam sido ameaçados na primeira versão da Base. Na perspectiva dos autores, a preocupação com a aprendizagem histórica dos estudantes e o papel que esta Base teria nesta configuração e definição de prioridades acabaram sendo pouco problematizados nas discussões, em relação a outras preocupações que foram postas no calor dos embates.

No segundo artigo do dossiê, intitulado Vitória da tradição ou resistência da inovação: o Ensino de História entre a BNCC, o PNLD e a Escola, as autoras Sandra Regina Ferreira de Oliveira e Flávia Eloisa Caimi, de certa forma, têm como ponto de partida algumas das conclusões do artigo anterior, pois partem da constatação do tipo de currículo que a BNCC estabeleceu para os Anos Finais deixar assim mesmo AF porque é uma etapa oficial do Ensino Fundamental (cronológico, linear, eurocêntrico, quadripartite), a fim de discutir como isso impacta o Programa Nacional do Livro Didático (PNLD), a partir do conceito de currículo (prescrito, editado e em ação) (SACRISTÁN, 2013).

Em um primeiro momento, abordam a BNCC evidenciando os pressupostos de formação histórica que permeiam esse documento e alguns de seus limites, bem como a "correlação direta entre os objetos de conhecimento e as habilidades a serem desenvolvidas", por meio de códigos alfanuméricos. Dentre estas habilidades, as de identificar, analisar, descrever e discutir são as mais recorrentes.

Tratando do PNLD, as autoras partem do Edital 2018 (BRASIL, 2015) e do Guia 2020, voltados aos Anos Finais do Ensino Fundamental, evidenciando o alinhamento, que já era esperado, com a BNCC, e a possível intenção de que esta articulação possa vir a ser utilizada para avaliação em larga escala do sistema de ensino. A partir daí, entre o currículo prescrito (BNCC) e o currículo editado (materializado no material didático), discutem o currículo em ação, lembrando que professores e estudantes, situados em dada cultura escolar, não necessariamente executarão a BNCC tal como está posta, uma vez que todo currículo se constrói no movimento, no processo, embora esta dimensão ainda esteja por ser estudada, em relação à BNCC.

O terceiro artigo, intitulado BNCC e Ensino de História: horizontes possíveis, de Adriana Soares Ralejo, Rafaela Albergaria Mello e Mariana de Oliveira Amorim, de certa maneira vai ao encontro da preocupação em relação a esse currículo em ação, mencionado no trabalho anterior. As autoras discutem possibilidades e limites que a BNCC traz para o ensino de História, a partir de algumas pesquisas que contemplam essa temática, e que parecem indicar um razoável consenso de que este documento referendou mais permanências no 
currículo escolar da disciplina, até em uma perspectiva retrógrada e conservadora, conforme os artigos anteriores já mencionavam, do que mudanças, em especial quanto aos conteúdos elencados e sua organização ao longo das séries.

A partir dos trabalhos que analisam a Base e sob a perspectiva da BNCC como um documento prescritivo, ao qual os docentes atribuirão um dado sentido em suas práticas, as autoras propõem a seguinte questão: "quais potencialidades e mudanças a BNCC pode gerar em nossas práticas docentes?". Para tanto, discutem as competências gerais estabelecidas no documento, para a garantia dos direitos de aprendizagem dos estudantes e, no caso da História em particular, a ideia de atitude historiadora, que visa a proporcionar um sentido ao aprendizado, o que é indicado pelas autoras como um potencial eixo de investimento para este ensino.

Os três primeiros artigos deste dossiê, portanto, trazem uma certeza em comum: a manutenção curricular, ou seja, a BNCC de História apresenta muito mais permanências do que mudanças. Nesta perspectiva, e considerando o que poderia ser observado como habitus, ou como regras do campo (BOURDIEU, 2004), em torno do currículo para o ensino de História, é possível pensar que para além dos embates acadêmicos, epistemológicos, políticos, econômicos, editoriais e pedagógicos que envolveram a BNCC para o ensino de História, esta acabou por traduzir, em sua versão final, uma acomodação a um currículo que, de certa forma, em sua estrutura geral, já estava e está consolidado em livros didáticos e em práticas docentes, inclusive, desde a formação desses docentes, via currículos de graduação das licenciaturas. Para além de algumas questões pontuais diferenciadas, ou por vezes, novos conceitos (ou velhos, repaginados) que reificam práticas consolidadas, seja por questões de acomodação a interesses políticos, corporativistas, de pesquisa, ou mesmo, a uma certa tradição do que se entende por ensinar História no senso comum e dentro das escolas (que, por vezes, se articula com áreas de pesquisa consolidadas na História), a ideia de mudança é sempre mais difícil de ser aceita. Articulada ao habitus, com todo o conforto que as certezas já acomodadas trazem, está mesmo uma lógica de sobrevivência e de realidade, que muitas vezes é ignorada ou subestimada no meio acadêmico em relação à ação docente na escola pública. $\mathrm{O}$ volume de turmas, séries, conteúdos, atividades, alunos com que estes docentes lidam cotidianamente exige a organização de uma prática, que vai se consolidando com as experiências e saberes ao longo de sua trajetória e que, embora seja possível e comum que incorporem mudanças e ajustes a ela, se estas são radicais e impostas (o famoso de cima para baixo, presente quando não há efetivamente diálogo na construção do documento), podem parecer inviáveis. Não estamos afirmando aqui que o que há é uma prática automatizada, ou pelo menos que não há somente isso, porque, com certeza, isso também existe, em todos os níveis de ensino. Mas consideramos que mudar toda uma lógica de pensar a disciplina, a 
organização dos conteúdos por série, de forma radical, pode ser uma perspectiva muito temerária e talvez até assustadora, na prática. De fato, uma mudança no currículo pode ser necessária e desejável, mas para isso, requereria uma melhor estratégia de construção, divulgação e implementação, articulada com ações de formação inicial e continuada de professores.

E se considerada a proposta de ruptura (mudança mais radical) da primeira versão da BNCC, sob a ótica dos conceitos mencionados, é muito fácil compreender a reação defensiva e agressiva que houve, que sempre será proporcional à medida da ruptura proposta. Embora as vozes dos professores das escolas de educação básica talvez tenham sido as menos ouvidas ou destacadas em toda a discussão da BNCC, parece certo que a versão final aprovada não mexe de forma estrutural com aquilo que já é consolidado como conteúdo escolar para a História, embora, com os códigos alfanuméricos, outras questões tenham sido agregadas.

A questão aqui não é tratarmos se a proposta era interessante, adequada, ou não; não se trata de discutir seu mérito, mas sim de afirmar como era absolutamente previsível a reação a ela, desde que se compreenda minimamente a lógica de funcionamento dos campos e agentes (e seus interesses), que se inter-relacionam. Da mesma forma, parece previsível que a solução de acomodação ao que já era consolidado, traria muito menos reação ou resistência, ao menos no chão da escola, pois embora mantenha a histórica problemática da disciplina (e não só da História) quanto à quantidade de conteúdos versus sua problematização ou aprofundamento, esta solução não muda radicalmente o que já era feito ou a existência desse problema. Além disso, essa manutenção também atende à tradição quadripartite que está configurada nas Universidades e nos currículos de graduação, inclusive de licenciatura. E em relação ao novo da BNCC (materializado por meio dos códigos alfanuméricos), os próximos editais e livros aprovados no PNLD deverão suprir essa demanda.

Mesmo a atitude historiadora, mencionada no terceiro artigo, não é inovadora. De certa forma e com outras palavras, vai ao encontro do pensamento histórico já presente nos PCNs, ou da consciência histórica de Jorn Rusen (mas sem que haja uma explicitação e vinculação teórica), e que anuncia a compreensão de que o ensino de História deve ir para além dos conteúdos, com uma perspectiva que relacione passado e presente (e futuro, no caso de Rusen).

Mas é importante destacarmos um aspecto que representa uma inovação, na perspectiva de uma intencionalidade regulatória e avaliativa mais claramente explicitada. Ao serem retomadas como princípio organizador do currículo, as competências e habilidades agora são apresentadas em uma codificação alfanumérica que as situa em relação à etapa da educação básica, ano escolar e sequência das habilidades. Por que esta forma de organização? Os PCNs 
elaborados na década de 1990 utilizavam um sistema conceitual baseado em objetivos gerais e específicos, conteúdos, critérios de avaliação, orientações e métodos didáticos, a serem mobilizados na organização e produção curricular para o ensino dos conteúdos propostos articulados aos temas transversais. Podese evidenciar neste documento uma forma de pensar o currículo ainda orientada por uma lógica inspirada na racionalidade técnica, mas que avançava na forma de abordar os conteúdos históricos a serem objeto de ensino. Nos PCNs para o Ensino Médio, a inovação marcante era a organização por área de conhecimentos, invertendo a lógica que presidira a organização curricular proposta pela Lei 5692/1971 (BRASIL, 1971) e que orientava o trabalho por área no então $1^{\circ}$. Grau, mantendo o ensino por disciplinas no $2^{\circ}$. Grau. Nos PCNs para o Ensino Médio, as competências e habilidades são apresentadas como forma de orientar o ensino-aprendizagem, acompanhadas de texto explicativo sobre o seu significado na área de Ciências Humanas e nas disciplinas que as constituem.

No documento Diretrizes Curriculares Nacionais, publicado em 2013 (BRASIL, 2013), a perspectiva normativa é apresentada em forma de diretrizes, baseadas em "direitos de aprendizagem", que devem orientar os processos educativos. Além das etapas, são apresentadas e discutidas as diferentes modalidades da educação básica com suas características e especificidades, o que representa uma inovação em perspectiva inclusiva que considera a diferença. Conforme destaca Macedo (2019, p. 47) "esta opção foi resultado de demanda de movimentos acadêmicos e sociais com vistas a distanciar a proposta da linguagem da testagem".

Estudos já publicados discutem a forma como a BNCC em sua versão final é orientada por uma perspectiva regulatória de organização curricular, etapista e atrelada à avaliação no âmbito das políticas de accountability (BALL, 2001): “Ao trazer de volta as competências - os PCN (do Ensino Médio) foram a primeira tentativa de hegemonizá-las--, a política curricular brasileira assume seus vínculos com um movimento internacional, que, sob a governança da OCDE, vem pondo em práticas avaliações internacionais comparativas" (MACEDO, 2019, p. 47).

O quarto artigo do dossiê, Trabalho e politica para ensinar História: apontamentos sobre a BNCC e a Educação Profissional e Tecnológica, de Bergston Luan Santos, trata da especificidade do ensino de História no âmbito do Ensino Médio Profissional, particularmente, a partir das categorias de trabalho e política, tal como trazidos na BNCC.

$\mathrm{O}$ autor situa a BNCC para o Ensino Médio, em que uma Educação Ética está anunciada como eixo articular; a área de conhecimento Ciências Humanas e suas Tecnologias, na qual a História está situada; e problematiza a questão da obrigatoriedade ou não da mesma no currículo, em função do eixo articulador indicado, entre outros elementos. Em relação às categorias Trabalho 
e Política, listadas entre aquelas que devem ser contempladas no Ensino Médio, discute seus potenciais para a reflexão e a formação para a cidadania, mas que ficam prejudicados, uma vez que, pelo dissolvimento da História nas Ciências Humanas, podem ser abordadas de forma atemporal, naturalizada e empobrecida. Neste sentido, acaba por apontar uma contradição interna na Base, na medida em que a anunciada atitude historiadora, mencionada no artigo anterior, ao menos no Ensino Médio, acaba por ser seriamente prejudicada.

O quinto artigo do dossiê, intitulado Ensinar História na Base Nacional Comum de Formação de Professores: a atitude historiadora convertendo-se em competências, escrito por Maria Aparecida Lima Santos, aborda relações entre a atitude historiadora proposta na BNCC de História, e a ideia de competências, trazida na Base Nacional Comum de Formação de Professores (BNCFP) (BRASIL, 2019). Neste sentido, a autora problematiza a representação de professor desejável, expressa na BNCFP, a ser formado, para que seja viabilizada a proposta da BNCC.

A BNCFP trata da formação de professores de forma geral, ou seja, orienta licenciaturas e, por isso, a discussão sobre a especificidade dessa proposta, em relação ao ensino de História, é importante para os fins desse dossiê. A autora destaca que neste documento não há uma definição precisa de competências, embora o termo seja recorrente, e o sentido e a caracterização que vão sendo agregados a ele estabelecem uma vinculação direta com a prática, o saber fazer. Ainda identifica que o conhecimento específico (no caso, histórico) fica subordinado à prática, com diminuição da formação teórica e ênfase em uma perspectiva assemelhada ao treinamento, caracterizando o que chama de neotecnicismo. Santos questiona que, no viés assumido no documento, em vez de um professor de História, orienta-se a formação de um professor que ensina História, podendo assim também ser problematizada qual a atitude historiadora que se espera do próprio docente, bem como de seus futuros estudantes.

A partir destas ponderações, e considerando os argumentos já apresentados acerca do currículo mantido na BNCC e da compreensão que os conceitos de habitus e de campo podem trazer para os embates que envolvem estes documentos prescritivos, é possível também problematizar a BNCFP, com sua ênfase na prática. A formação de professores, desde o modelo $3+1$, traz ranços que são muito difíceis de superar e que ainda se manifestam em muitos currículos de cursos de graduação para licenciatura em História, sendo estes configurados também, como o currículo escolar, em algumas acomodações, sendo que uma delas ainda é a relação (ou a falta dela) entre os conteúdos específicos e o conhecimento histórico propriamente dito, e a sua dimensão pedagógica, o ensino de. 
Talvez seja possível pensar em duas situações extremas, sendo que o equilíbrio e o diálogo necessário entre ambas ainda estejam por ser construídos, e não será um documento prescritivo que conseguirá alterar essa configuração, mas somente uma construção conjunta, pelos envolvidos nesse lugar de fronteira (MONTEIRO; PENNA, 2011) que é o ensino de História: uma predominância de conteúdos específicos da História, sem que sejam refletidos em seu sentido pedagógico, ou seja, ênfase em o que ensinar e uma predominância de como ensinar, voltada para a prática, sem a necessária base epistemológica e teórica para subsidiar a reflexão sobre o porquê, o para que e o para quem ensinar, reflexão esta imprescindível para a docência (GONÇALVES; MONTEIRO, 2017).

A discussão sobre a formação de professores continua no artigo Educação para as Relações Étnico-Raciais e a formação de professores de História nas novas diretrizes para a formação de professores!, de Mauro Cezar Coelho e Wilma Nazaré Baía Coelho. Nele, os autores tratam de uma dimensão específica dessa formação, qual seja, o preparo de docentes para o enfrentamento do racismo e seus desdobramentos e, com esta reflexão, contribuem com um exemplo muito concreto, acerca de algumas das críticas feitas por Santos à BNCFP.

Para tanto, realizam uma extensa análise documental, identificando em 47 cursos de licenciatura em História do país o espaço e a forma de abordagem da Educação para as relações étnico-raciais. Confirmam a predominância do saber historiográfico nesta formação, e que estão relegadas a um segundo plano duas dimensões essenciais para a docência na educação básica: "a especificidade do saber histórico escolar e o contexto da educação brasileira e do público atendido por ela", o que envolve necessariamente a diversidade étnica e cultural.

Em relação à BNCFP, constatam que neste documento, as Diretrizes Curriculares Nacionais para Educação para as Relações Étnico-Raciais, igualmente aprovadas pelo Conselho Nacional de Educação em 2004, e ainda vigentes, são ignoradas. Analisando as competências gerais, as competências específicas e as habilidades que a BNCFP estabelece para os professores, os autores identificam o predomínio de habilidades técnicas (em consonância com o artigo de Maria Aparecida Lima Santos, mas sob outra perspectiva teórica), e a ausência de habilidade voltada ao reconhecimento e ao trato de questões étnico-raciais, e ao enfrentamento do racismo e de seus desdobramentos. Este silenciamento do documento, se articulado à permanência do viés eurocêntrico $\mathrm{e}$ quadripartite na BNCC, indica escolhas sobre, no mínimo, o não enfrentamento deste grave problema que ainda permeia o currículo, a escola e a nossa sociedade.

Este conjunto de artigos relativos a dimensões diversas da BNCC e da BNCFP, pensando especificidades do ensino de História no Brasil, permitem-nos observar como antigos desafios são agora articulados a 
proposições políticas que não buscam enfrentá-los, mas que os ignoram, por vezes prescrevendo ou silenciando sobre prescrições que potencialmente os agravarão, ou, no mínimo, contribuirão para sua manutenção. O que está posto é um sentido para a educação básica e para a formação de professores para ela, em que o predomínio do fazer, do como e do aplicar é muito claro, em detrimento do compreender, do refletir e do conhecer no sentido de uma consciência histórica mais elaborada, crítica e significativa.

\section{Bases Nacionais e o Ensino de História no Brasil e em outros países}

O próximo conjunto de artigos focaliza questões relacionadas às políticas curriculares em abordagem comparada entre a realidade brasileira e de outros países. No sétimo artigo do dossiê Possibilidades na luta pelo ensino de histórias negras na era das bases nacionais curriculares no Brasil e nos Estados Unidos: a Lei 10639/03 e os National History Standards, Jessika Rezende Souza da Silva e Amílcar Araújo Pereira abordam o ensino de História em perspectiva transnacional, colocando em diálogo as experiências da Lei Federal 10.639/2003, no Brasil, e dos National History Standards [Padrões de História Nacional], da década de 1990, nos Estados Unidos, na luta pelo reconhecimento do protagonismo dos negros e da diversidade das suas trajetórias nos currículos escolares. A abordagem é realizada considerando o contexto no qual a implantação de bases curriculares nacionais tem se disseminado no mundo globalizado, com o intento de efetivar modelos de conteúdos e habilidades que preparem os estudantes para responder a testes classificatórios e padronizados. Ao mesmo tempo, focaliza iniciativas do movimento negro em âmbito transnacional que, investindo em propostas mais democráticas e inclusivas, lutam para romper com o eurocentrismo e o racismo, que historicamente têm estruturado padrões curriculares presentes na educação, tanto no Brasil quanto nos EUA. Os autores apontam algumas semelhanças e diferenças, entre elas, o papel dos docentes em suas escolas na implementação dessas mudanças, bem como a reação conservadora que tem buscado travar ou impedir o avanço dessas políticas. $\mathrm{O}$ artigo oferece, também, importante contribuição para a discussão sobre o lugar estratégico do currículo prescrito nos embates políticos para a construção de uma educação democrática.

No artigo O jardim do vizinho é mais bonito ou está mais longe de nossos olhos? Um olhar sobre a BNCC de História no Brasil e os NAPs na Argentina sobre os conteúdos do passado recente, Helenice Aparecida Bastos Rocha e 
Maria Paula Gonzalez apresentam uma análise comparativa da apropriação da história recente, sobretudo das ditaduras militares, em dois documentos oficiais que orientam a definição dos currículos nacionais - a Base Nacional Comum Curricular (BNCC) brasileira e os Núcleos de Aprendizagens Prioritárias (NAP) argentinos, dois países que vivenciaram experiências de regimes autoritários na segunda metade do século XX. O tema ganha relevância no momento atual, marcado pela proliferação de discursos negacionistas e justificadores das violações dos direitos humanos cometidas durante os regimes ditatoriais na América do Sul.

O artigo apresenta uma visão geral sobre o contexto de criação da BNCC e o tratamento desse conteúdo, fazendo o mesmo, a seguir, para os NAPs, analisando como esse passado recente é narrado para as novas gerações na forma de temas de ensino e aprendizagem. Na análise, as autoras investigam as necessidades sociais visadas na estruturação desses documentos, bem como os sentidos atribuídos a essas experiências, focalizando as opções definidas na apropriação do debate historiográfico. É interessante destacar as diferentes formas de recepção desses documentos nos dois países: rejeição e crítica no Brasil, e apoio e aceitação na Argentina, o que nos leva a refletir sobre análises de cunho generalizante realizadas sobre propostas curriculares e seus efeitos.

Brasil, Colômbia e México. Políticas curriculares recentes para o ensino de História e das Ciências Sociais na educação básica e a formação inicial dos professores, texto de autoria de Léia Adriana da Silva Santiago, Martha Cecilia Gutiérrez Giraldo, e Paulina Lapatí Escalante, apresenta uma síntese dos propósitos que orientam as propostas curriculares para o ensino de História e Ciências Sociais no Brasil, Colômbia e México, desde o final do século XX e no decorrer do século XXI, evidenciando que estas têm sido dependentes de políticas de governo e reformas que respondem mais às visões hegemônicas e às disputas entre disciplinas, do que aos objetivos de formação dos cidadãos. A análise das políticas de formação inicial de professores dessas mesmas disciplinas, nos três países, evidencia a forma como respondem às recomendações de organismos internacionais, o que tem levado à desvalorização da importância da formação para o magistério nessas áreas do conhecimento. As autoras concluem afirmando que ainda é necessária a realização de pesquisas sobre a formação inicial de professores de História e Ciências Sociais que contribuam, não só para a melhor compreensão das questões envolvidas nesta formação, como também no âmbito da docência na educação básica.

De alguma forma, o artigo intitulado $O$ ensino de história e ciências sociais na educação primária na Colômbia: das políticas curriculares às práticas educacionais, de autoria de Diana Marcela Arana Hernández e Martha Cecilia Gutiérrez Giraldo, oferece contribuição no sentido proposto pelas autoras do 
artigo que o antecede, ao apresentar resultados de pesquisa realizada sobre o ensino de História e Ciências Sociais na educação primária na Colômbia, focalizando a relação entre as políticas curriculares e a prática dos professores. Apresentando, inicialmente, uma síntese do que tem sido o ensino de História e Ciências Sociais nesse país nas últimas décadas, as autoras problematizam a relação entre formação inicial, prática docente e políticas governamentais focalizando docentes em início de carreira, quando, geralmente, muitas críticas são feitas à insuficiência da formação inicial para o enfrentamento dos desafios da docência. A prática de dois professores iniciantes do ensino fundamental que lecionam em instituições públicas de ensino é objeto de análise por meio de um estudo de caso, tendo por base a questão: o que pensam está relacionado com o que fazem na prática, no que diz respeito aos fins de ensino das Ciências Sociais, considerando os propósitos previstos nessas políticas? Os resultados apresentam duas experiências que coincidem nos objetivos que os professores propõem (críticos) e se diferenciam nos propósitos que se evidenciam em suas práticas (um positivista e outro crítico). Os resultados possibilitam questionar o significado dos debates sobre as políticas governamentais para o ensino das Ciências Sociais e o que ocorre com a formação inicial de professores generalistas para o ensino dessas ciências.

Nestes quatro artigos foram analisadas questões relacionadas ao ensino de História e Ciências Sociais nos Estados Unidos e em países da América Latina: a implementação de políticas antirracistas, a abordagem de questões pertinentes a regimes ditatoriais recentes e, de modo mais abrangente, a discussão sobre os efeitos das políticas educacionais preconizadas por organismos multilaterais nos currículos prescritos, na autonomia dos professores e na prática docente. Essa discussão atravessa os artigos e evidencia uma preocupação presente no campo do currículo: como resistir/se insurgir às novas formas de regulação da ação docente que têm sido implementadas nos diferentes países por meio de instrumentos criados no âmbito das políticas de responsabilização?

Entre diferentes autores que têm questionado essas políticas, Zeichner (2010) aponta a insatisfação gerada frente a políticas de desprofissionalização, de ataque às instituições universitárias de formação docente e de privatização da educação. Nóvoa também nos alerta sobre este "projeto político da privatização que tem sido conduzido em nome da "salvação" da dimensão pública da educação" e que tem como contrapartida a desqualificação da formação oferecida nas instituições universitárias, segundo seus detratores muito voltada para os aspectos teóricos em detrimento da abordagem das questões práticas (NÓVOA, 2017, p. 1110).

Macedo (2019), além de discutir as vinculações destas políticas aos organismos multilaterais, e seus desdobramentos, focaliza o uso das competências e habilidades como forma de apresentação e organização das 
disciplinas escolares que, além de esvaziar suas dimensões sociais, culturais e políticas, estabelece padrões compatíveis com práticas de avaliação institucionais - nacionais e internacionais - contribuindo assim para aprofundar mecanismos de regulação e controle da formação e da prática docente.

Fechando o dossiê, temos o artigo intitulado O currículo de História em Inglaterra, Portugal e Espanha: contextos diferentes e problemas comuns de autoria de Antoni Santisteban-Fernández, Alfredo Dias Gomes, e Edda Sant Obiols, no qual a análise é realizada tendo por base um mesmo esquema interpretativo: inicialmente, uma descrição do contexto e da tradição curricular, posteriormente, a análise dos diferentes elementos do currículo. Finalidades, escalas temporais e espaciais, conteúdos e enfoque metodológico são focalizados nos currículos voltados para a educação secundária obrigatória em cada país, embora as idades dos estudantes nessas etapas não coincidam com exatidão. O estudo evidencia que existem diferenças entre os três países considerando o processo de elaboração e debates sobre o currículo, ou as prioridades definidas. O papel do professorado ao tomar decisões sobre o que e como ensinar, a utilidade da História para compreender o mundo atual, a formação do pensamento histórico, bem como a relação entre educação histórica e a educação para a cidadania, são objeto de análise. A abordagem comparativa possibilita a compreensão das diferenças entre os três países, bem como os encaminhamentos diferenciados na forma de lidar com problemas comuns.

Após a leitura deste artigo, é possível perceber que a autonomia dos professores para definir o desenvolvimento curricular, a forma de abordagem da escala temporal na sua organização e os encaminhamentos para a formação do pensamento histórico são questões focalizadas em seus diferentes contextos. Mas cabe destacar um aspecto que não foi objeto de atenção no artigo, mas que salta aos olhos do leitor ao observar os conteúdos indicados nos três países: o eurocentrismo que prevalece na seleção definida e que, com certeza, afeta a formação para a cidadania dos estudantes ao refletir sobre a relação com outras sociedades, principalmente aquelas constituídas como ex-colônias, com suas demandas e posicionamentos no contexto contemporâneo das relações internacionais.

Questões relacionadas às políticas curriculares e seus efeitos nos permitem, em perspectiva comparada, perceber como, mesmo em contexto de imposição de políticas que buscam produzir um "comum" por meio do currículo, a atenção volta-se, na maioria dos artigos, para a busca da diferença, das alternativas encontradas para insurgências, que apresentam alguns aspectos similares, mas que expressam sentidos atribuídos, possíveis, aos contextos nos quais se desenvolvem. Certamente há desafios que estão presentes em vários países, como aqueles mencionados no artigo sobre o ensino de História e Ciências Sociais na educação primária na Colômbia: a formação generalista dos professores dos 
Anos Iniciais e o ensino da História e das Ciências Sociais, desafio também verificado no Brasil, bem como os efeitos do desenvolvimento das políticas educacionais a partir de organismos multilaterais.

\section{Considerações finais}

Observando o conjunto de artigos que compõem este dossiê, e sob a perspectiva de campo de Pierre Bourdieu, talvez possamos pensar que elementos epistemológicos da História e do ensino de História perpassem as preocupações de pesquisadores de diferentes países, permitindo-nos identificar algumas similaridades, como princípios relativamente comuns que estão presentes nestes trabalhos. Por exemplo, destacamos um viés de fundo humanista na abordagem e na função do ensino de História; a preocupação com uma formação de professores de História, desde o que no Brasil temos como Anos Iniciais, que envolva uma fundamentação epistemológica e pedagógica, necessária para uma docência que compreenda a escola e o ensino de História como espaços de formação crítica, inclusiva, e fundamentada no conhecimento científico; e críticas a políticas internacionais, que envolvem interesses econômicos sobre a educação, e que se contrapõem à formação considerada desejável, crítica, reflexiva e humanista.

Em meio a tantos debates e questionamentos sobre a BNCC, verificados no Brasil, principalmente no que se refere à disciplina História, a organização deste Dossiê teve por objetivo abrir espaço para que pesquisadores do ensino desta disciplina se posicionassem e apresentassem apropriações e contextualizações evidenciadas em suas pesquisas. A política que orienta a elaboração dessa Base não é exclusividade brasileira, como podemos notar nos artigos que o compõem. Integra um projeto internacional que vê nas políticas de accountability alternativas para a melhoria da qualidade da educação e uniformização de padrões e parâmetros educacionais. Neste projeto, menciona-se o nacional, mas a forma de apresentação e o uso das "competências e habilidades", associadas ao Programa Internacional de Avaliação de Estudantes (PISA) ${ }^{1}$, podem levar a um processo de homogeneização pautado por interesses do desenvolvimento econômico global, preocupação que também perpassa outros trabalhos aqui apresentados.

1 Tradução de Programme for International Student Assessment, é um estudo comparativo internacional realizado a cada três anos pela Organização para a Cooperação e Desenvolvimento Econômico (OCDE). 
Nesse sentido, conforme Macedo (2019) nos alerta, é preciso estarmos atentos para a postura do MEC no atual governo que, diferentemente do governo Temer, não tem dado destaque à BASE: não há referência a ela no site oficial nem no Programa de governo, cuja direção se volta para a deslegitimação da escola como espaço público de formação e socialização, o que também é abordado e fundamentado por Penna (2016). A autora sugere que o posicionamento ultraconservador é contrário a uma base curricular que representa uma intervenção do Estado, que negaria à família o direito de educar suas crianças e adolescentes de acordo com seus valores e princípios.

Esse Dossiê foi produzido em 2020/2021, em pleno contexto pandêmico, no qual o ensino remoto se tornou realidade com aprofundamento radical das desigualdades econômicas, sociais e educacionais. Famílias que defendiam a educação domiciliar já reveem suas posições. As competências e habilidades propostas já precisam ser repensadas considerando-se as demandas para o acesso e implementação do ensino remoto. O movimento antirracista se ampliou e apresenta demandas de igualdade incontornáveis, bem como o movimento feminista e LGBTQ+ por reconhecimento de suas pautas identitárias e de direitos. Por outro lado, o movimento ultraconservador de direita, representado pelo atual governo federal, ainda subsiste com apoio de cerca de um pouco menos de $30 \%$ da população, o que demarca muitos embates ainda por vir.

Uma Base está prescrita. Há muitos elementos que estão sendo organizados para sua implementação, como diretrizes curriculares estaduais e municipais, os critérios estabelecidos pelo Programa Nacional do Livro Didático, e a Base Nacional para Formação de Professores. Mas é nas mãos de professoras e professores que o currículo se faz, acontece em escolas e salas de aula presenciais e virtuais. E que possam se organizar em associações representativas como a Associação Brasileira de Pesquisa em Ensino de História (ABEH), assumindo tais discussões e desenvolvendo proposições alternativas, considerando os contextos culturais, sociais e políticos nos quais a educação democrática se constitui e constitui sujeitos.

\section{REFERÊNCIAS}

BALL, Stephen J. Diretrizes políticas globais e relações políticas locais em educação. Currículo sem fronteiras, [s.l.], v. 1, n. 2, p. 99-116, 2001. Disponível em: https:// gestaoeducacaoespecial.ufes.br/sites/gestaoeducacaoespecial.ufes.br/files/field/anexo/ ball.pdf. Acesso em: 20 mar. 2021. 
BOURDIEU, Pierre. Os usos sociais da ciência: por uma sociologia clínica do campo científico. São Paulo: Editora Unesp, 2004.

BRASIL. Ministério da Educação. Lei nº 9.394, de 20 de dezembro de 1996. Estabelece as diretrizes e bases da educação nacional. Brasília, DF: 1996. Disponível em: https:// presrepublica.jusbrasil.com.br/legislacao/109224/lei-de-diretrizes-e-bases-lei-9394-96 Acesso em: 21 maio 2021.

BRASIL. Ministério da Educação. Diretrizes Curriculares Nacionais da Educação Básica. Brasília, DF: MEC, 2013. Disponível em: http://portal.mec.gov.br/diretrizescurriculares nacionaisparaaeducacaobasica. Acesso em: 20 mar. 2021.

BRASIL. Ministério da Educação. Fundo Nacional de Desenvolvimento da Educação. Edital de Convocação 04/2015 - CGPLI. Edital de Convocação para o processo de inscrição e avaliação de obras didáticas para o Programa Nacional do Livro Didático PNLD 2018. A União por meio do Ministério da Educação (MEC), [...] obras didáticas destinadas aos estudantes e professores do ensino médio da rede pública. Brasília, DF: FNDE, 14 dez. 2015. Disponível em: https://www.fnde.gov.br/index.php/programas/ programas-do-livro/consultas/editais-programas-livro/item/7932-pnld-2018. Acesso em: 20 mar. 2021.

BRASIL. Ministério da Educação. Base Nacional Comum Curricular. Brasília, DF: MEC, 2017. Disponível em: http://basenacionalcomum.mec.gov.br/images/BNCC_EI_ EF_110518_versaofinal_site.pdf. Acesso em: 20 mar. 2021.

BRASIL. Ministério da Educação. Resolução CNE/CP n. 2, de 20 de dezembro de 2019. Define as Diretrizes Curriculares Nacionais para a Formação Inicial de Professores para a Educação Básica e institui a Base Nacional Comum para a Formação Inicial de Professores da Educação Básica (BNC-Formação). Brasília, DF: MEC, 20 dez. 2019. Disponível em: http://portal.mec.gov.br/index.php?option=com_docman\&view=downl oad\&alias=133091-pcp022-19-3\&category_slug=dezembro-2019-pdf\&Itemid=30192. Acesso em: 20 mar. 2021.

BRASIL. Presidência da República. Lei $n^{\circ}$ 5.692, de 11 de agosto de 1971. Fixa Diretrizes e Bases para o ensino de $1^{\circ}$ e $2^{\circ}$ graus, e dá outras providências. Brasília, DF: Presidência da República, 11 ago. 1971. Disponível em: https://www2.camara.leg.br/ legin/fed/lei/1970-1979/lei-5692-11-agosto-1971-357752-publicacaooriginal-1-pl.html. Acesso em: 21 maio 2021.

CERRI, Luis Fernando. O ensino de História como objeto de pesquisa e de ação educativa: a atualidade de uma Associação Brasileira de Ensino de História. HHMagazine - Humanidades em Rede, 21 dez. 2018. Disponível em: https://hhmagazine.com.br/oensino-de-historia-como-objeto-de-pesquisa-e-de-acao-educativa-a-atualidade-de-umaassociacao-brasileira-de-ensino-de-historia/. Acesso em: 20 mar. 2021.

GONÇALVES, Nadia Gaiofatto; MONTEIRO, Ana Maria Ferreira da Costa. Saberes e práticas docentes e ensino de História: temas, conceitos e referenciais (1970-2014). 
Educação em Revista, Belo Horizonte, v. 33, e156257, 2017. Disponível em: http://www. scielo.br/scielo.php?script=sci_arttext\&pid=S0102-46982017000100112\&lng=en\&nrm =iso. Acesso em: 20 mar. 2021.

GONÇALVES, Nadia Gaiofatto. Produção sobre Ensino de História em periódicos acadêmicos brasileiros (1970-2016). In: RALEJO, Adriana; MONTEIRO, Ana Maria Ferreira da Costa. Cartografias da pesquisa em ensino de História. Rio de Janeiro: Mauad X, 2019. p. 113-126.

MACEDO, Elizabeth Fernandes. Fazendo a Base virar realidade: competências e o germe da comparação. Revista Retratos da Escola, Brasília, v. 13, n. 25, p. 39-58, jan./maio 2019. Disponível em: http://retratosdaescola.emnuvens.com.br/rde/article/view/967. Acesso em: 20 mar. 2021.

MARTINS, Maria do Carmo. A história prescrita e disciplinada nos currículos escolares: quem legitima esses saberes? Bragança Paulista: EDUSF, 2002.

MESQUITA, Ilka M. D. Memórias/identidades em relação ao ensino e formação de professores de história: diálogos com fóruns acadêmicos nacionais. 2008. 269 f. (Doutorado em Educação) - Programa de Pós-Graduação em Educação, Universidade Estadual de Campinas, Campinas, SP. Disponível em: http://repositorio.unicamp.br/ bitstream/REPOSIP/252062/1/Mesquita_IlkaMigliode_D.pdf. Acesso em: 20 mar. 2021.

MONTEIRO, Ana Maria Ferreira da Costa. Formação de professores: entre demandas e projetos. Revista História Hoje, São Paulo, v. 2, n. 3, p. 19-42, 2013. Disponível em: https://rhhj.anpuh.org/RHHJ/article/view/63. Acesso em: 20 mar. 2021.

MONTEIRO, Ana Maria Ferreira da Costa; PENNA, Fernando de Araújo. Ensino de História: saberes em lugar de fronteira. Educação \& Realidade, Porto Alegre, v. 36, n. 1, p. 191-211, jan-abr. 2011. Disponível em: https://seer.ufrgs.br/educacaoerealidade/ article/view/15080. Acesso em: 20 mar. 2021.

NÓVOA, António. Firmar a posição como professor, afirmar a profissão docente. Cadernos de Pesquisa, São Paulo, v. 47, n. 166, p. 1106-1133, out./dez. 2017. Disponível em: http:// www.scielo.br/scielo.php?script=sci_arttext\&pid=S0100-15742017000401106\&lng=en \&nrm=iso. Acesso em: 20 mar. $202 \overline{1}$.

PENNA, Fernando de Araújo. Programa "Escola sem Partido": uma ameaça à educação emancipadora. In: GABRIEL, Carmen Teresa; MONTEIRO, Ana Maria Ferreira da Costa; MARTINS, Marcus Leonardo Bomfim (org.). Narrativas do Rio de Janeiro nas aulas de História. Rio de Janeiro: Mauad X, 2016. p. 43-58.

SACRISTÁN, José Gimeno (org.). Saberes e incertezas sobre o currículo. Porto Alegre: Penso, 2013.

SCHMIDT, Maria Auxiliadora Moreira dos Santos. História do ensino de História no Brasil: uma proposta de periodização. Revista de História da Educação - RHE, Porto Alegre, v. 16, n. 37, p. 73-91, maio/ago. 2012. Disponível em: http://seer.ufrgs.br/index. php/asphe/article/view/24245/pdf. Acesso em: 20 mar. 2021. 
SILVA, Monica Ribeiro da. A BNCC da reforma do Ensino Médio: o resgate de um empoeirado discurso. Educação em Revista, Belo Horizonte, v. 34, e214130, 2018. Disponível em: http://www.scielo.br/scielo.php?script=sci_arttext\&pid=S010246982018000100301\&lng=pt\&nrm=iso. Acesso em: 20 mar. 2021.

ZEICHNER, Kenneth. Competition, economic rationalization, increased surveillance, and attacks on diversity: neo-liberalism and the transformation of teacher education in the U.S. Teaching and Teacher Education, [s.l.], v. 26, n. 8, p. 1544-1552, 2010. Disponível em: https:/www.sciencedirect.com/science/article/abs/pii/S0742051X10000843. Acesso em: 20 mar. 2021.

Texto recebido em 06/04/2021.

Texto aprovado em 21/05/2021. 